\title{
Weight assessment and the provision of weight management advice in primary care: a cross-sectional survey of self- reported practice among general practitioners and practice nurses in the United Kingdom
}

Nathan Critchlow ${ }^{1,2^{*}}$ (D) Gillian Rosenberg ${ }^{1}$, Harriet Rumgay ${ }^{3}$, Robert Petty ${ }^{1}$ and Jyotsna Vohra ${ }^{1}$

\begin{abstract}
Background: Although primary care settings provide a large-scale and high-reach opportunity for weight management and obesity prevention, the proportion of adults in the United Kingdom (UK) who report receiving weight management advice is limited. This study examines the self-reported frequency of assessing weight and providing weight management advice by General Practitioners (GPs) and Practice Nurses (PNs) working in primary care in the UK, and differences by practitioner characteristics.

Methods: Cross-sectional survey with GPs and PNs in the UK ( $n=2020)$, conducted January-March 2017. A mock consultation exercise assessed what factors led to calculating a patient's Body Mass Index (BMI) and whether weight management advice was given after determining the patient had an obese BMI. For all patients, practitioners were asked how often they calculated BMI, how often they gave weight management advice to patients with an obese BMI, and how often they utilised different advice or referral options (each: Always/Often vs. Less often/Never). Binary logistic regressions examined whether frequency of assessing weight and providing advice was associated with practitioner characteristics.

\footnotetext{
* Correspondence: nathan.critchlow@stir.ac.uk

${ }^{1}$ Cancer Policy Research Centre, Cancer Research UK, 2 Redman Place, London E20 1JQ, UK

${ }^{2}$ Institute for Social Marketing and Health, Faculty of Health Sciences and Sport, University of Stirling, Stirling FK9 4LA, UK

Full list of author information is available at the end of the article
}

(c) The Author(s). 2020 Open Access This article is licensed under a Creative Commons Attribution 4.0 International License, which permits use, sharing, adaptation, distribution and reproduction in any medium or format, as long as you give appropriate credit to the original author(s) and the source, provide a link to the Creative Commons licence, and indicate if changes were made. The images or other third party material in this article are included in the article's Creative Commons licence, unless indicated otherwise in a credit line to the material. If material is not included in the article's Creative Commons licence and your intended use is not permitted by statutory regulation or exceeds the permitted use, you will need to obtain permission directly from the copyright holder. To view a copy of this licence, visit http://creativecommons.org/licenses/by/4.0/ The Creative Commons Public Domain Dedication waiver (http://creativecommons.org/publicdomain/zero/1.0/) applies to the data made available in this article, unless otherwise stated in a credit line to the data. 
(Continued from previous page)

Results: In the mock consultation, physical cues (40\%) were most likely to prompt calculation of BMI, and half of practitioners (56\%) provided weight management advice after determining the patient had an obese BMI, with GPs less likely to do so than PNs (Odds Ratio $[O R]=0.59,95 \%$ Cl: $0.47-0.75)$. Half of practitioners (58\%) said they calculated the BMI of all patients Always/Often, with GPs less likely to do so than PNs (OR=0.27, 95\% Cl: $0.21-0.34)$. Three quarters (78\%) said they provided weight management advice to patients with an obese BMI Always/Often, with GPs less likely to do so than PNs (OR=0.63, 95\% Cl: $0.47-0.85)$. Weight management advice was provided more frequently than referrals, particularly suggesting increased physical activity (93\%) and diet modification (89\%).

Conclusions: Consistent with previous research, the findings suggest that opportunities to provide weight management advice in primary care, including to patients with an obese BMl, are potentially missed. Future research should test alternative mechanisms to increase weight assessment and advice provision, examine the effectiveness of advice frequently given, and seek solutions to reported barriers for providing weight management advice.

Keywords: Obesity, Weight management, Primary care, Survey, Weight assessment, Overweight, General practitioners, Nurses, Obesity policy

\section{Background}

In England, over a third (35.6\%) of adults have an overweight Body Mass Index (BMI) and almost another third (28.7\%) have an obese BMI [1]. In 2017/2018, there were 10,660 hospital admissions directly linked to obesity in England and nearly three quarters of a million admissions where obesity was a factor [2]. This has economic implications, as the National Health Service (NHS) spends an estimated $£ 6.1$ billion on overweight and obesity-related ill-health each year, and the wider costs to society are estimated at $£ 27$ billion [3]. Obesity has also personal health implications, for example it is linked to multiples types of cancer [4] and over 20,000 cancer cases each year in the United Kingdom (UK) [5].

As most of the population in the UK are registered with a General Practitioner (GP) practice [6], primary care settings provide a large-scale and high-reach opportunity for obesity intervention and prevention. Research suggests that well-planned and adequately resourced brief interventions delivered in primary care can be effective in stimulating weight loss, particularly when discussions generate referrals to specialist weight management services [7-15]. In the UK, primary care practitioners are therefore encouraged to instigate brief conversations to help identify at-risk patients (including calculating BMI as part of their assessment), explain behaviour modifications that would lead to weight reductions, and make referrals to specialist weight management services if required [16]. Similar brief interventions are also advised for smoking cessation and higher-risk alcohol consumption [17-19].

Patients believe that primary care practitioners play an important role in weight management are expectant they will discuss the issue if required [20,21], while primary care practitioners similarly acknowledge they play a key role in obesity prevention [22, 23]. A nationally representative survey, however, suggests that only around a fifth of adults in the UK have received advice about weight management from a healthcare practitioner, including less than half of those who had an obese BMI [24]. This is despite the same study finding that almost all adults had seen a healthcare practitioner in the past year. These trends are corroborated in wider examinations of patient records, self-reported frequency of assessing weight and providing referrals among primary care practitioners, and observations of primary care consultations [11, 25-32]. Moreover, even when weight is assessed and a referral to a specialist weight management service is made, only around a third of patients reportedly attend the referral at all and fewer complete the referral in full [33]. Combined, research therefore suggests that opportunities to provide weight management advice to patients in primary care settings, including those at risk, are potentially being missed.

Examining self-reported provision of weight management advice among primary care practitioners provides important insight into perceived normative practice. Although there is existing research concerning this topic in the UK, most studies are based on smaller qualitative samples, only focus on specific parts of the UK, or only focus on certain practitioner groups. There is a need for larger studies which examine self-reported practice across the UK and assess to what extent, if at all, there is variation among primary care practitioners (e.g. by experience, role, or country). In response, we examine self-reported provision of weight management advice among a large sample of GPs and Practice Nurses (PNs) from across the UK. We examine what factors prompt weight assessment in primary care, how often they report providing weight management advice, what advice or referrals are provided frequently, and how provision of weight management advice varies by practitioner characteristics.

\section{Methods \\ Design and sample}

An online cross-sectional survey was conducted with primary care health practitioners in the UK $(n=2020)$. Data were collected between January and March 2017. 
The survey only included PNs and GPs; other health professionals, such as physiotherapists and dentists, were excluded through screening questions. ResearchNow (now called Dynata), the market research company who conducted the survey, recruited a convenience sample through their existing panel of health professionals. A survey weight was provided to enable descriptive data to be representative of participant country within the UK (England, Scotland, Wales, and Northern Ireland). The survey included sections about the delivery of brief advice related to weight, smoking [34], and alcohol consumption in primary care. This study only focuses on the data concerning weight management. The survey design and content was developed and piloted using a health professional panel made up of eight Cancer Research UK health facilitators who work with primary care practitioners [34].

\section{Measures}

\section{Primary care practitioner characteristics}

Practitioners were asked to self-report their gender, age (coded: $18-39$ years, $40-59$ years, $\geq 60$ years), healthcare professional role (GP or PN), years qualified (coded: 05 years, $6-10$ years, $11-15$ years, $16-20$ years, $\geq 20$ years), typical days worked in general practice per week (coded: 1-2 days, 3-4 days, 5-6 days), approximate list size of practice where they worked (coded: $\leq 2000$ patients; 2000-5000; 5000-10,000; 10,000-20,000; $\geq 20,000)$, and in which Clinical Commissioning Group (CCG [35]) or Health Board $[36,37]$ their practice was located. The latter variable was used to assign country (coded: England, Scotland, Wales, and Northern Ireland).

\section{Providing weight management advice in a mock consultation}

To prompt whether practitioners would provide weight management advice during a typical patient consultation, participants were presented with a brief mock scenario in the form of a short written vignette. Use of vignettes to prompt practitioner reactions have been used elsewhere in primary care research [38-40]. Vignettes were tailored for GPs and PNs to reflect the different types of patients that they would typically consult in primary care. For GPs, the brief vignette read 'Maya is a 52 year old female who presents with a persistent cough'. For PNs, the brief vignette read 'Maya is a 52 year old female who presents with a burn that requires wound management'. Consultations deliberately did not present issues directly related to weight to avoid response bias. Three questions were asked in response to this prompt.

First, practitioners were asked what factors were most likely to result in them calculating the patient's BMI. They were presented with seven response options: [1] previous weight-related health condition [2]; weightassociated symptoms [3]; physical cues, e.g. size/body shape [4]; computer prompts [5]; incentives payments [6]; known increased or high BMI from medical records [7]; National Institute for Health and Care Excellence [NICE] weight loss guidelines; and [8] other reasons, with free text box provided. Practitioners could only select one option.

Second, practitioners were then prompted with the statement 'Maya has a BMI of 32 and asks whether her weight is a problem. How would you respond?' A free text box was provided for answers. Free text responses were binary coded based on whether the practitioner's answer suggested they would provide weight management advice, take action (e.g. make a referral), or start a conversation about weight management (Yes/No). Answers coded as 'No' included simply informing the patient they were overweight, stating the associated health risks of being overweight, or other unclear or administrative actions (e.g. checking medical records). One member of the research team manually coded all response options, and a second researcher subsequently checked the coding. Any discrepancies or uncertainty was discussed and agreed between the two researchers.

Third, practitioners were asked the minimum BMI which would lead to them starting a conversation with the patient about weight management. Answers were provided on a scale from 20.0 to 40.0 BMI. Answers were coded as being within either the healthy ([Min]20.0-24.9), overweight (25.0-29.9), or obese $(>30.0)$ BMI range for adults.

\section{Frequency of calculating BMI for all patients}

Practitioners were asked to think about all the patients they had seen at their practice in the last year and asked 'How often did you calculate a patient's BMI?' Answers were provided on a five-point scale $(1=$ Always $-5=$ Never $)$ and binary coded $(1=$ Always/Often, $0=$ Less often/Never $)$.

\section{Provision of weight management advice to patients with an obese BMI}

Practitioners were asked 'Thinking now about all the patients that you saw in the last year who are obese (with a recorded BMI of 30-35), how often did you provide weight management advice?' Answers were provided on a fivepoint scale $(1=$ Always $-5=$ Never $)$ and binary coded ( 1 = Always/Often, $0=$ Less often/Never).

\section{Advice and referrals in weight management}

Practitioners were promoted with 'For all patients in the last year that you gave advice about weight management, how often did you ...' ' and then provided with 14 outcomes, including 5 examples of advice (e.g. increase physical activity or diet modification) and eight examples of referrals (e.g. make a referral to a dietician/healthy 
eating course within the practice) (see Table 5 for full details). Answers to each option were provided on a five-point scale $(1=$ Always $-5=$ Never $)$ which was binary coded $(1=$ Always $/$ Often, $0=$ Less often $/$ Never $)$.

\section{Analysis}

All data were analysed using SPSS version 24 (SPSS Inc., Chicago). Weighted and unweighted frequencies were calculated for practitioner characteristics. Weighted frequencies were also calculated for each of the main study variables, for example what factor was most likely to stimulate calculation of BMI in the mock consultation and whether BMI was calculated for all patients Always/ Often (vs. Less often/Never). For each variable, Pearson Chi-square tests examined differences by gender, age, days spent in practice in a typical week, years qualified, list size of the practice, and country.

Binary logistic regression models examined to what extent, if at all, weight assessment and provision of weight management advice was associated with practitioner characteristics. Four models were computed: [1] whether weight management advice was given in the mock consultation (Yes/No) [2]; the minimum BMI that would instigate a conversation about weight management in the mock consultation (obese $B M I$ vs. overweight $B M I$ ) [3]; how often BMI was calculated for all patients (Always/Often vs. Less often/Never); and [4] how often weight management advice was given to those with a BMI in the obese range (Always/Often vs. Less often/ Never). Gender, age group, typical days worked in practice, practitioner role, years qualified, list size of practice, and country of residence were included as covariates. Reference categories for categorical variables with $\leq 2$ levels (e.g. practitioner role) are reported in the results. For country, the simple $=$ contrast function compared each of Scotland, Wales, and Northern to England. For days worked in practice, years qualified and list size, both which had $\geq 3$ levels and were ordinal data, the contrast = difference function enabled comparison of each increasing category relative to the combined preceding levels. For example, the first comparison for years qualified was $6-10$ years versus $0-5$ years, whereas the next was $11-15$ years versus less often (i.e. combined 0 5 and 6-10 years categories). The binary regressions were conducted on unweighted data, as the variable used to construct weights (country) was included as a covariate.

\section{Results}

\section{Sample characteristics}

In the weighted sample, there was an even proportion of GPs and PNs (Table 1). Most GPs were male (62\%), aged 40-59 years old (55\%), based in England (84\%), and typically worked in practice at least 3-4 days per week. More than half of GPs had been qualified for $\geq 16$ years and worked in a practice with a list size of at least 5000 patients. Almost all PNs were female (95\%). The majority of PNs were aged 40-59 years old (65\%), based in England (84\%), typically worked in practice 3-4 days per week (61\%), had been qualified $\geq 20$ years (56\%), and worked in practice with a list size of at least 5000 patients. Overall, practitioners came from 234 CCGs or Health Boards across the UK, suggesting good geographical coverage.

\section{Mock consultation: what factors most likely lead to calculating BMI?}

In the mock consultation, physical cues were identified by most practitioners as the factor most likely to prompt them to calculate the patient's BMI (40\% of practitioners). This was followed by weight-related symptoms (29\%) and computer prompts (12\%) (Table 2). Compared to PNs, Chi-square tests found that GPs were more likely to calculate BMI due to physical cues $(p=0.036, \phi(\mathrm{Phi})=0.05)$, weight-related symptoms $(p<0.001, \phi=0.22)$, and incentives $(p<0.001, \phi=0.08)$. Compared to GPs, PNs were more likely to calculate BMI due to computer prompts $(p<0.001, \phi=-0.20)$, previous weight-related health conditions $(p=0.003, \phi=-0.07)$, knowing about increasing BMI from medical records $(p<0.001, \phi=-0.15)$, and for other reasons $(p<0.001, \phi=-0.09)$.

\section{Mock consultation: responding to patient $\mathrm{BMI}$ of 32}

When prompted with the statement 'Maya has a BMI of 32 and asks whether her weight is a problem. How would you respond?' around half of practitioners (56\%) provided a free text answer coded as giving advice about weight management, taking action, or starting a conversation about weight management. A binary logistic regression found that responding with advice, action, or starting a conversation was lower in males compared to females (Adjusted Odds Ratio $[A O R]=0.70, p=0.004)$ and among GPs compared to PNs $(A O R=0.59, p<0.001)$ (Table 3$)$. Responding with advice, action or starting a conversation was greater for practitioners in Wales $(A O R=1.74, p=0.016)$ and Scotland $(A O R=1.40, p=0.043)$, compared to England.

\section{Mock consultation: minimum BMI that would initiate conversation about weight}

After accounting for missing data ( $n=77$, weighted), approximately half of practitioners $(52 \%)$ said the minimum BMI that would trigger a conversation about weight management in the mock consultation would be in the overweight range (BMI: 25.0-29.9), while almost half $(45 \%)$ said within the obese range (BMI $\geq 30.0)$. Only a minority $(3 \%)$ said they would have a conversation when BMI was in the healthy range (BMI 20.024.9). A binary logistic regression found that initiating a conversation about weight when the patient was in the overweight $\mathrm{BMI}$ range (versus obese) was lower in males compared to females $(A O R=0.59, p<0.001)$, in GPs 
Table 1 Weighted sample characteristics, by practitioner role

\begin{tabular}{|c|c|c|c|c|c|c|}
\hline \multirow[t]{2}{*}{ Characteristics } & \multicolumn{2}{|c|}{ Overall $(n=2020)$} & \multicolumn{2}{|c|}{ PNs $(n=1014)$} & \multicolumn{2}{|c|}{ GPs $(n=1006)$} \\
\hline & $\%$ & $n$ & $\%$ & $n$ & $\%$ & $n$ \\
\hline \multicolumn{7}{|l|}{ Gender } \\
\hline Female & 66 & 1339 & 95 & 960 & 38 & 378 \\
\hline Male & 34 & 681 & 5 & 54 & 62 & 627 \\
\hline \multicolumn{7}{|l|}{ Age } \\
\hline $18-39$ years & 34 & 680 & 28 & 280 & 40 & 400 \\
\hline 40-59years & 60 & 1216 & 65 & 662 & 55 & 554 \\
\hline $60+$ years & 6 & 124 & 7 & 72 & 5 & 52 \\
\hline \multicolumn{7}{|l|}{ Country } \\
\hline England & 84 & 1693 & 84 & 852 & 84 & 841 \\
\hline Scotland & 9 & 172 & 8 & 82 & 9 & 90 \\
\hline Wales & 5 & 99 & 5 & 51 & 5 & 48 \\
\hline Northern Ireland & 3 & 57 & 3 & 30 & 3 & 27 \\
\hline \multicolumn{7}{|c|}{ Typical days in general practice } \\
\hline 1-2 days per week & 7 & 149 & 9 & 91 & 6 & 58 \\
\hline 3-4 days per week & 59 & 1184 & 61 & 619 & 56 & 565 \\
\hline 5-6 days per week & 34 & 687 & 30 & 304 & 38 & 383 \\
\hline \multicolumn{7}{|l|}{ Years qualified } \\
\hline $0-5$ years & 8 & 171 & 8 & 82 & 9 & 89 \\
\hline $6-10$ years & 15 & 308 & 12 & 120 & 19 & 188 \\
\hline $11-15$ years & 16 & 331 & 13 & 133 & 20 & 198 \\
\hline $16-20$ years & 15 & 306 & 11 & 115 & 19 & 191 \\
\hline More than 20 years & 45 & 905 & 56 & 565 & 34 & 340 \\
\hline \multicolumn{7}{|l|}{ List size at practice } \\
\hline$<2000$ & 4 & 76 & 6 & 58 & 2 & 18 \\
\hline $2000-5000$ & 15 & 314 & 15 & 151 & 16 & 163 \\
\hline $5000-10,000$ & 37 & 739 & 34 & 348 & 39 & 391 \\
\hline $10,000-20,000$ & 36 & 717 & 33 & 336 & 38 & 381 \\
\hline$>20,000$ & 5 & 107 & 6 & 64 & 4 & 43 \\
\hline Unsure & 3 & 67 & 6 & 58 & 1 & 9 \\
\hline
\end{tabular}

\section{Notes}

Data are weighted

$1=$ Practice Nurse

${ }^{2}=$ General Practitioner.

compared to PNs $(A O R=0.59, p<0.001)$, and for practitioners in Wales compared to England $(A O R=0.63, p=$ 0.041) (Table 3).

\section{Frequency of calculating BMI for all patients}

When asked to consider all patients they had seen at their practice in the past year, almost three-fifths of practitioners (58\%) said that they had calculated BMI always or often. A binary logistic regression indicated that assessing BMI Always/Often (vs. Less often/Never) was lower in males compared to females $(A O R=0.71, p=$ 0.006), in those from Scotland compared to England $(A O R=0.69, p=0.030)$, and in GPs compared to PNs
$(A O R=0.27, p<0.001)($ Table 4$)$. There was also a main association of typical days worked in practice $(p<0.001)$, with those who worked more days per week more likely to measure BMI Always/Often.

Providing weight management advice to all patients with obese BMI

Practitioners were asked to consider how often, in the past year, they had given weight management advice to patients with an obese BMI. Over three quarters of practitioners $(78 \%)$ said they had provided advice to such patients Always/Often. A binary logistic regression found that providing advice Always/Often was lower in males 
Table 2 Factors most likely to prompt calculation of Body Mass Index (BMI) in mock consultation, by practitioner role

\begin{tabular}{|c|c|c|c|c|c|c|c|c|}
\hline \multirow[t]{2}{*}{ Prompt } & \multicolumn{2}{|c|}{ Overall } & \multicolumn{2}{|c|}{$P N^{1}$} & \multicolumn{2}{|c|}{$\mathrm{GPS}^{2}$} & \multicolumn{2}{|c|}{ Chi-Square } \\
\hline & $\%$ & $n$ & $\%$ & $n$ & $\%$ & $n$ & $\overline{x^{2}}$ & $p$ \\
\hline Physical cues (e.g. body size) & 40 & 813 & 38 & 385 & 43 & 428 & 4.40 & 0.036 \\
\hline Weight-related symptoms & 29 & 585 & 19 & 193 & 39 & 392 & 97.83 & $<0.001$ \\
\hline Computer prompt & 12 & 238 & 18 & 183 & 6 & 55 & 76.89 & $<0.001$ \\
\hline Previous weight-related health condition & 7 & 136 & 8 & 85 & 5 & 51 & 8.76 & 0.003 \\
\hline Known increasing or high $\mathrm{BMI}^{3}$ from medical records & 6 & 128 & 10 & 102 & 3 & 26 & 47.54 & $<0.001$ \\
\hline Incentives payments & 2 & 42 & 1 & 9 & 3 & 33 & 14.25 & $<0.001$ \\
\hline NICE weight loss guidelines & 2 & 36 & 2 & 23 & 1 & 13 & 2.74 & n.s. \\
\hline Other & 2 & 41 & 3 & 34 & 1 & 7 & 17.90 & $<0.001$ \\
\hline \multicolumn{9}{|c|}{$\begin{array}{l}\text { Notes } \\
\text { Base = All participants; Data and analyses are weighted } \\
\text { Response options are sorted by proportion }(\%) \text { reported, based on overall sample } \\
1=\text { Practice Nurse. } \\
2^{2}=\text { General Practitioner. } \\
{ }^{3}=\text { Body Mass Index }(B M I), \text { n.s not significant }(p>0.05)\end{array}$} \\
\hline
\end{tabular}

compared to females $(A O R=0.60, p<0.001)$, those in Northern Ireland compared to England $(A O R=0.40, p=$ $0.001)$, and in GPs compared to PNs $(A O R=0.63, p=$ 0.002) (Table 4). There was also a main association of typical days worked in practice $(p=0.01)$, with those who typically worked 5-6 days per week more likely to provide advice Always/Often than those who worked less frequently $(A O R=1.57, p=0.003)$.

\section{Weight management advice given to patients with an obese BMI}

Practitioners were asked to consider how often, in the past year, they had provided different weight management advice to patients with an obese BMI (each coded: Always/Often vs. Less often/Never). The majority of practitioners said they would suggest increased physical activity (93\%) or diet modification (89\%) Always/Often, while around half (49\%) said they would suggest arranging a follow-up appointment to discuss or provide information leaflets (46\%) (Table 5). A third (32\%) said they would suggest keeping a food diary always or often.

Bivariate Pearson Chi-square tests found that PNs were more likely than GPs to Always/Often suggest arranging a follow-up appointment $(p<0.001, \phi=-0.23)$, provide information leaflets $(p<0.001, \phi=-0.39)$ or suggest keeping a food diary $(p<0.001, \phi=-0.19)$ (Table 5). Compared to PNs, Chi-square tests found that GPs were more likely to suggest increasing physical activity $(p=0.002, \phi=0.07)$. There was no difference between GPs and PNs for suggesting diet modification.

\section{Weight management referrals given to patients with an obese BMI}

Practitioners were asked to consider how often, in the past year, they had given different referral options to patients with an obese BMI (each coded: Always/Often vs.
Less often/Never). Approximately a quarter said they would always or often refer patients to an external exercise referral scheme (26\%), an NHS weight management programme external to the practice $(24 \%)$, or a dietician or healthy eating course external to the practice $(23 \%)$. Around a fifth said that they would refer patients to a dietician or healthy eating course internal to the practice (20\%) or to an NHS weight management programme in the practice $(17 \%)$ (Table 5$)$. At least one-in-10 practitioners said that they would refer patients to a commercial weight loss programme (14\%) or an exercise referral scheme internal to the practice (13\%). Less than one-in10 said that they would provide a prescription (7\%).

Compared to GPs, Chi-square tests found that PNs were more likely to refer patients Always/Often for six of the eight outcomes (Table 5). The only exceptions were providing prescriptions, an outcome more likely among GPs $(p<0.001, \phi=0.09)$, and referral to exercise referral scheme external to the practice, where there was no difference between GPs and PNs.

\section{Discussion}

By exploring self-reported practice among a large sample GPs and PNs, and examining differences by practitioner characteristics, we provide further understanding about weight assessment and the provision of weight management advice in UK primary care settings. Concerning assessment, around half of practitioners reported that they frequently calculated BMI in all patients, however no single factor prompted the majority to do this in the mock consultation. Concerning advice, only around half of practitioners provided weight management advice in the mock consultation after determining that the patient had an obese BMI. This estimate is lower than was selfreported for all patients seen in the last year who had an 
Table 3 Binary logistic regressions exploring the association between practitioner characteristics and (1) whether weight management advice was provided in mock consultation and (2) whether conversations would be initiated at overweight or obese Body Mass Index (BMI)

\begin{tabular}{|c|c|c|c|c|c|c|}
\hline \multirow[t]{2}{*}{ Variables/Reference categories } & \multicolumn{3}{|c|}{ Provide advice to mock consultation BMI of $32 ?^{1,3,5}$} & \multicolumn{3}{|c|}{ What BMI trigger weight management conversation? ${ }^{\mathbf{2}, \mathbf{4}, \mathbf{6}}$} \\
\hline & $A O R$ & $95 \% \mathrm{Cl}$ & $p$ & $A O R$ & $95 \% \mathrm{Cl}$ & $p$ \\
\hline \multicolumn{7}{|l|}{ Gender } \\
\hline Female & REF & - & - & REF & - & - \\
\hline Male & 0.70 & $0.55-0.89$ & 0.004 & 0.59 & $0.46-0.76$ & $<0.001$ \\
\hline \multicolumn{7}{|l|}{ Age } \\
\hline 18-39years old & REF & - & n.s. & REF & - & n.s. \\
\hline 40-59 years old (vs younger) & 1.08 & $0.79-1.49$ & n.s. & 1.20 & $0.86-1.67$ & n.s. \\
\hline$\geq 60$ years old (vs younger) & 1.00 & $0.65-1.55$ & n.s. & 0.77 & $0.49-1.21$ & n.s. \\
\hline \multicolumn{7}{|l|}{ Country } \\
\hline England & REF & - & 0.024 & REF & & 0.052 \\
\hline Scotland (vs. Eng) & 1.40 & $1.01-1.93$ & 0.043 & 0.79 & $0.57-1.09$ & n.s. \\
\hline Wales (vs. Eng) & 1.74 & $1.11-2.73$ & 0.016 & 0.63 & $0.41-0.98$ & 0.041 \\
\hline Northern Ireland (vs. Eng) & 0.95 & $0.57-1.58$ & n.s. & 0.65 & $0.38-1.13$ & n.s. \\
\hline \multicolumn{7}{|l|}{ Days in practice in week } \\
\hline $1-2$ days & REF & - & n.s. & REF & - & n.s. \\
\hline 3-4 days (vs. less often) & 1.01 & $0.69-1.47$ & n.s. & 0.81 & $0.53-1.21$ & n.s. \\
\hline 5-6 days (vs. less often) & 0.81 & $0.63-1.03$ & n.s. & 1.11 & $0.85-1.45$ & n.s. \\
\hline \multicolumn{7}{|l|}{ Health professional role } \\
\hline Practice nurse & REF & - & - & REF & - & - \\
\hline General practitioner & 0.59 & $0.47-0.75$ & $<0.001$ & 0.59 & $0.47-0.76$ & $<0.001$ \\
\hline \multicolumn{7}{|l|}{ Years qualified } \\
\hline $0-5$ years & REF & - & n.s. & REF & - & n.s. \\
\hline 6-10 years (vs. more recent) & 0.91 & $0.61-1.35$ & n.s. & 0.90 & $0.60-1.37$ & n.s. \\
\hline 11-15 years (vs. more recent) & 0.95 & $0.70-1.30$ & n.s. & 0.80 & $0.57-1.10$ & n.s. \\
\hline 16-20 years (vs. more recent) & 0.92 & $0.65-1.31$ & n.s. & 0.86 & $0.60-1.23$ & n.s. \\
\hline$\geq 20$ years (vs. more recent) & 1.02 & $0.77-1.35$ & n.s. & 0.89 & $0.66-1.20$ & n.s. \\
\hline \multicolumn{7}{|l|}{ List size } \\
\hline$\leq 2000$ patients. & REF & - & n.s. & REF & - & n.s. \\
\hline 2000-5000 patients (vs less) & 1.30 & $0.77-2.18$ & n.s. & 1.20 & $0.67-2.11$ & n.s. \\
\hline 5000-10,000 patients (vs less) & 1.12 & $0.83-1.51$ & n.s. & 1.09 & $0.79-1.52$ & n.s. \\
\hline $10,000-20,000$ patients (vs less) & 1.21 & $0.95-1.53$ & n.s. & 0.90 & $0.70-1.16$ & n.s. \\
\hline$\geq 20,000$ patients (vs less) & 0.77 & $0.51-1.17$ & n.s. & 1.14 & $0.73-1.79$ & n.s. \\
\hline
\end{tabular}

\section{Notes}

Base $=$ All participants; $A O R=$ Adj. Odds Ratio; $95 \% \mathrm{Cl}=95 \%$ Confidence Interval, n.s. non-significant $(p>0.05)$

Data are not weighted, as country included as a covariate

${ }^{1} \mathrm{DV}=$ Provided advice, conversation or referral in response to prompt (Yes $=1 ; \mathrm{No}=0$ ).

${ }^{2} \mathrm{DV}=$ Min BMI that would trigger weight conversation (Overweight $=1$; Obese $=0$ ).

${ }^{3}$ Test of coefficients, $X^{2}(17)=95.21, p<0.001$; Hosmer \& Lemeshow, $X^{2}(8)=12.43, p=0.13$, Nagelkerke $R^{2}=0.06$.

${ }^{4}$ Test of coefficients, $X^{2}(17)=108.18, p<0.001$; Hosmer \& Lemeshow, $X^{2}(7)=2.86, p=0.90$, Nagelkerke $R^{2}=0.08$.

${ }^{5}$ Cases excluded due to missing data on one or more variable $(n=68)$.

${ }^{6}$ Cases excluded due to missing data on one or more variable $(n=193)$.

obese BMI, in which around three quarters said they frequently provided weight management advice, albeit this may be related to the explicitness of the latter question. Concerning action, practitioners reportedly provided weight management advice more frequently than referrals, particularly suggestions to increase physical activity and modify diet.

Clinical guidelines [41], performance indicators [42], and recommendations of best practice $[16,43]$ suggest that practitioners working in primary care in the UK 
Table 4 Binary logistic regressions exploring associations between practitioner characteristics and (1) frequency of calculating patient BMI (all patients) and (2) frequency of providing weight management advice to obese patients

\begin{tabular}{|c|c|c|c|c|c|c|}
\hline \multirow[t]{2}{*}{ Variables/Reference categories } & \multicolumn{3}{|c|}{ How often calculate patient BMI? ${ }^{1,3,5}$} & \multicolumn{3}{|c|}{ How often provide weight management advice to obese patients? ${ }^{\mathbf{2 , 4 , 6}}$} \\
\hline & $A O R$ & $95 \% \mathrm{Cl}$ & $p$ & $A O R$ & $95 \% \mathrm{Cl}$ & $p$ \\
\hline \multicolumn{7}{|l|}{ Gender } \\
\hline Female & REF & - & - & REF & - & - \\
\hline Male & 0.71 & $0.55-0.91$ & 0.006 & 0.60 & $0.45-0.80$ & $<0.001$ \\
\hline \multicolumn{7}{|l|}{ Age } \\
\hline 18-39years old & REF & - & n.s. & REF & - & n.s. \\
\hline 40-59years old (vs younger) & 1.06 & $0.76-1.49$ & n.s. & 1.09 & $0.74-1.59$ & n.s. \\
\hline$\geq 60$ years old (vs younger) & 1.04 & $0.65-1.64$ & n.s. & 0.92 & $0.54-1.54$ & n.s. \\
\hline \multicolumn{7}{|l|}{ Country } \\
\hline England & REF & - & n.s. & REF & & 0.006 \\
\hline Scotland (vs. Eng) & 0.69 & $0.50-0.97$ & 0.030 & 0.76 & $0.53-1.10$ & n.s. \\
\hline Wales (vs. Eng) & 1.17 & $0.74-1.86$ & n.s. & 0.96 & $0.57-1.63$ & n.s. \\
\hline Northern Ireland (vs. Eng) & 1.00 & $0.56-1.66$ & n.s. & 0.40 & $0.24-0.68$ & 0.001 \\
\hline \multicolumn{7}{|l|}{ Days in practice in week } \\
\hline $1-2$ days & REF & - & $<0.001$ & REF & - & 0.010 \\
\hline 3-4 days (vs. less often) & 1.64 & $1.12-2.44$ & 0.013 & 1.28 & $0.83-1.98$ & n.s. \\
\hline 5-6 days (vs. less often) & 1.70 & $1.30-2.21$ & $<0.001$ & 1.57 & $1.16-2.12$ & 0.003 \\
\hline \multicolumn{7}{|l|}{ Health professional role } \\
\hline Practice Nurse & REF & - & - & REF & - & - \\
\hline General practitioner & 0.27 & $0.21-0.34$ & $<0.001$ & 0.63 & $0.47-0.85$ & 0.002 \\
\hline \multicolumn{7}{|l|}{ Years qualified } \\
\hline $0-5$ years & REF & - & n.s. & REF & - & n.s. \\
\hline 6-10 years (vs. more recent) & 1.27 & $0.84-1.92$ & n.s. & 0.71 & $0.44-1.16$ & n.s. \\
\hline 11-15 years (vs. more recent) & 1.13 & $0.82-1.57$ & n.s. & 1.06 & $0.73-1.55$ & n.s. \\
\hline 16-20 years (vs. more recent) & 1.26 & $0.87-1.82$ & n.s. & 0.84 & $0.55-1.27$ & n.s. \\
\hline$\geq 20$ years (vs. more recent) & 1.13 & $0.83-1.52$ & n.s. & 1.07 & $0.75-1.53$ & n.s. \\
\hline \multicolumn{7}{|l|}{ List size } \\
\hline$\leq 2000$ patients. & REF & - & n.s. & REF & - & n.s. \\
\hline 2000-5000 patients (vs less) & 1.62 & $0.94-2.79$ & n.s. & 1.85 & $1.00-3.41$ & n.s. \\
\hline 5000-10,000 patients (vs less) & 1.22 & $0.89-1.68$ & n.s. & 1.22 & $0.85-1.75$ & n.s. \\
\hline $10,000-20,000$ patients (vs less) & 1.11 & $0.86-1.42$ & n.s. & 1.04 & $0.78-1.38$ & n.s. \\
\hline$\geq 20,000$ patients (vs less) & 1.08 & $0.69-1.69$ & n.s. & 1.21 & $0.71-2.07$ & n.s. \\
\hline
\end{tabular}

Notes

Base $=$ All participants; $A O R=$ Adj. Odds Ratio; $95 \% \mathrm{Cl}=95 \%$ Confidence Interval; n.s. $=$ non-significant $(p>0.05)$

Data are not weighted, as country included as covariate

${ }^{1} \mathrm{DV}=$ How often calculate BMI of patient (Always/often $=1$; Less often $=0$ ).

${ }^{2} \mathrm{DV}=$ How often provide weight management advice to obese patients (Always/often $=1$; Less often $=0$ ).

Model summaries for final block:

${ }^{3}$ Test of coefficients, $x^{2}(17)=270.13, p<0.001$; Hosmer \& Lemeshow, $x^{2}(8)=4.29, p=0.83$, Nagelkerke $R^{2}=0.17$.

${ }^{4}$ Test of coefficients, $X^{2}(17)=79.54, p<0.001$; Hosmer \& Lemeshow, $X^{2}(8)=5.78, p=0.67$, Nagelkerke $R^{2}=0.06$.

${ }^{5}$ Cases excluded due to missing data on one or more variable $(n=68)$.

${ }^{6}$ Cases excluded due to missing data on one or more variable $(n=68)$.

should regularly assess patient BMI and, where required, instigate discussions about weight management and make appropriate referrals to weight management services. In this study, however, only around half of practitioners provided weight management advice in the mock consultation, only around half said they frequently assessed BMI among all patients, and only three quarters said they frequently provided weight management advice to patients with an obese BMI. These findings are therefore consistent with infrequent reports of providing or 
Table 5 What advice or referrals did GPs and PNs provide always or often (vs less often) in weight management advice in the past year?

\begin{tabular}{|c|c|c|c|c|c|c|c|c|}
\hline \multirow[t]{2}{*}{ Advice or referral activities } & \multicolumn{2}{|c|}{ Overall } & \multicolumn{2}{|c|}{$P N^{1}$} & \multicolumn{2}{|c|}{$\mathrm{GPS}^{2}$} & \multicolumn{2}{|c|}{ Chi-Square } \\
\hline & $\%$ & $n$ & $\%$ & $n$ & $\%$ & $n$ & $\overline{x^{2}}$ & $p$ \\
\hline \multicolumn{9}{|l|}{ Advice } \\
\hline Increase physical activity & 93 & 1879 & 91 & 926 & 95 & 953 & 9.48 & 0.002 \\
\hline Diet modification & 89 & 1801 & 88 & 893 & 90 & 908 & 2.70 & n.s. \\
\hline Arrange follow-up appointment to discuss & 49 & 979 & 60 & 609 & 37 & 370 & 109.08 & $<0.001$ \\
\hline Provide information leaflet & 46 & 939 & 66 & 670 & 27 & 269 & 313.23 & $<0.001$ \\
\hline Keep food diary & 32 & 649 & 41 & 415 & 23 & 234 & 72.04 & $<0.001$ \\
\hline \multicolumn{9}{|l|}{ Referral } \\
\hline Refer to external exercise referral scheme & 26 & 514 & 27 & 274 & 24 & 240 & 2.67 & n.s. \\
\hline Refer to NHS weight management programme external to practice & 24 & 475 & 26 & 262 & 21 & 213 & 5.99 & 0.014 \\
\hline Refer to external dietician/healthy eating course & 23 & 458 & 25 & 253 & 20 & 205 & 5.96 & 0.015 \\
\hline Refer to internal dietician/healthy eating course & 20 & 405 & 23 & 232 & 17 & 173 & 10.10 & 0.001 \\
\hline Refer to NHS weight management programme in practice & 17 & 336 & 22 & 225 & 11 & 111 & 45.05 & $<0.001$ \\
\hline Refer to commercial weight loss programme & 14 & 286 & 17 & 173 & 11 & 113 & 14.12 & $<0.001$ \\
\hline Refer to internal exercise referral scheme & 13 & 270 & 17 & 174 & 10 & 96 & 25.22 & $<0.001$ \\
\hline Provide prescription (e.g. Orlistat / Xenical / Alli) & 7 & 146 & 5 & 50 & 10 & 96 & 16.02 & $<0.001$ \\
\hline
\end{tabular}

\section{Notes}

Base $=$ All participants; Data and analyses are weighted by country

All data coded Always/Often vs. Less often (e.g. Sometimes, Occasionally, Never); \% shown are those providing Always/often

$1=$ Practice Nurse.

$2=$ General Practitioner.

n.s. non-significant $(p>0.05)$

receiving advice in patient research, self-report research with primary care practitioners, observations of consultations, and examinations of patient records [24-32].

Research with primary care practitioners has suggested several barriers to routinely discussing weight with patients, which may partly explain these findings. Examples include lack of time or competing priorities, knowledge of obesity guidelines or relevant training, concerns of sensitivity or negative consequences (e.g. upsetting patients), and scepticism about the efficacy of advice [22, 23, 44-51]. Similar themes have also been reported in patient-focused research [20,21,31]. Some of these barriers are also reportedly aggravated among GPs, in particular concerns about moving the consultation away from the patient's agenda, and harming their doctorpatient relationship [45]. This may help to explain why PNs were more likely to report frequently assessing BMI and more likely to provide weight management. This is in addition to wider suggestions that believing weight to be part of their chronic disease and health promotion remit, confidence in their ability to build patient rapport, and being encouraged to attend training and make time for weight management may also facilitate more frequent weight management practice among PNs [22, 45, 52]. That almost all PNs were female also explains why gender was also associated with greater likelihood of, or more frequent, weight management practice. Wider factors which may also influence provision of weight assessment and management include adequate local-level funding, practitioner knowledge of available and effective referral opportunities, tensions around whether obesity is a medical or social problem, and effective communication between primary care and weight management services $[14,15,53]$.

The findings highlight four considerations for future practice and research. First, no single factor was identified by the majority of practitioners as prompting them to calculate BMI. Future research should therefore explore whether increased emphasis on any of the lesser reported prompts could increase assessment and advice provision, with previous research supporting the potential efficacy of computer prompts $[54,55]$, financial incentives [56, 57], or multicomponent interventions [14]. It is also important that any alternatives are implemented in a manner that reduces, or avoids exacerbating, concerns among patients that they are being stigmatised [31] or existing barriers reported among practitioners. Put simply, continued examination and evaluation of what works, and why, for practitioners and patients is essential. Second, only around half of practitioners said the minimum BMI that would trigger a conversation about weight management was in the overweight range. Given the potential effectiveness of brief primary care advice [7-14], research should explore 
whether increasing the proportion of earlier interventions in the overweight range reduces escalation to obesity and some of the perceived barriers (e.g. concerns about offending patients). Third, the findings highlight what forms of advice or referrals were used most frequently. Further examination is needed to determine the efficacy and cost-effectiveness of these actions, how they compare to alternative options given less frequently, and what barriers exist to providing referrals versus advice (e.g. availability of local services or patient receptiveness). For example, research with patients has suggested that perceived simplistic advice around consumption and exercise, the two forms of advice provided most frequently in this study, may have limited resonance with some patients [31]. Finally, it is possible that differences in weight management practice between GPs and PNs, and the barriers reported elsewhere [44-51], may relate to inherent differences in their professional roles, responsibilities, and nature of patient contact. It may, therefore, be beneficial for research to further examine PN and GPs separately to examine best practice, barriers, and opportunities for focussed interventions among each group.

There are limitations. The data are cross-sectional and only show associations between provision of weight management and practitioner characteristics, they cannot determine underlying causal influence. Practitioners were drawn from a convenience sample recruited by a market research company, and findings may not be representative of all GPs and PNs working in primary care. The data only come from a single time point in early 2017, and may not be representative of other times of the year or changes in practice since data collection. The data were self-reported, and therefore provision of weight management advice may be underestimated due to errors in recall or outcomes not included as response options. The possibility of response bias cannot be discounted, particularly when the question implied what the logical practice was (e.g. giving weight management advice to patients with an obese BMI).

A further important limitation is that the mock consultation only provided a limited example of patient contact, and it cannot be known if practitioners would have reacted different in-person (e.g. using non-verbal cues) or if the original health concern was different or had links to weight. We also acknowledge that providing written descriptions of how they would respond in the mock consultation does not reflect the discursive and verbal nature of how this advice is actually given. The mock consultation also cannot fully reflect or accurately recreate important contextual aspects of consultations, namely existing patient relationships, prior knowledge of the patient's weight behaviour or health conditions, or time limitations. Introducing this information into the vignette could have biased responses (i.e. if stating presence or absence of health conditions), reduced applicableness to some practitioners (e.g. newly qualified practitioners may not have longstanding patient relationships), or reduced generalisability to some contexts (e.g. a prior relationship is a not prerequisite for all primary care consultation scenarios). Other methods, such as observations during practice or qualitative interviews, are better equipped to examine the relative influence of contextual factors.

\section{Conclusion}

By exploring the self-reported behaviour of a large sample GPs and PNs, and differences by practitioner characteristics, we provide further understanding about weight assessment and the provision of weight management advice in UK primary care settings. For assessment, only around half of practitioners reported frequently calculating BMI, and there was no single factor likely to prompt the majority of practitioners to do this. Only around half of practitioners provided weight management advice in the mock consultation, despite being informed that the patient had an obese BMI, and only three-quarters said they did this frequently for all patients with an obese BMI. Concerning action, practitioners provided weight management advice to patients with obese BMI more frequently than referrals. The findings highlight several potential next steps for research and practice. These include testing what prompts are effective in instigating assessment of obesity (without upsetting patients), examining the relative impact of earlier intervention with overweight (but not yet obese) patients, and examining the cost-effectiveness and efficacy of different advice and referral options. These steps may help to increase provision of weight management conversations in primary care, enhance the preventative input these services have, and overcome some of the reported barriers.

\section{Abbreviations \\ AOR: Adjusted Odds Ratio; BMI: Body Mass Index; CCG: Clinical Commissioning Group; Cl: Confidence Intervals; GP: General Practitioner; n.s.: No significance (i.e. $p<0.05$ ); NICE: National Institute for Clinical Excellence; PN: Practice Nurse; UK: United Kingdom}

\section{Acknowledgements \\ The authors pay thanks to the health professionals and academics who helped design and refine the survey. We also thank ResearchNow (now Dynata) for their support in conducting the piloting, fieldwork, and initial data cleaning. We pay particular thanks to the GPs and PNs who took the time to complete the survey; without them we simply could not have conducted this research. We also thank Jack Birch for his comments and advice during the write up and team members from the Cancer Policy Research Centre for their helpful discussions and conversations.}

\section{Authors' contributions}

$G R, R P, H R$, and JV were responsible for study design, development of the survey, and data acquisition. GR and HR coded the free-text response options from the mock consultation, conducted preliminary analysis of the data, and carried out initial interpretation of the results. NC planned and carried out the main data analysis. NC led on interpretation of the main analysis, 
with support from GR and HR. NC drafted the manuscript. All authors provided feedback and approved the final version of the manuscript.

\section{Funding}

The research was carried out as part of the Cancer Policy Research Centre's (CPRC) research portfolio at Cancer Research UK. It was not part of any specific external research grant awarded by Cancer Research UK. NC was a paid research consultant at the CPRC during his involvement in the research (funding ID

WT1111341). Through the co-authors (listed at the start; all employed by the CPRC at the time of study), Cancer Research UK were involved in the study inception, study design, commissioning of fieldwork, initial analyses, and data interpretation. Their specific contributions are listed below.

\section{Availability of data and materials}

The datasets used and/or analysed during this study are available from the corresponding author, or the Cancer Policy Research Centre at Cancer Research UK, on reasonable request.

\section{Ethics approval and consent to participate}

Approval was granted by the University of Stirling NHS, Invasive or Clinical Research Ethics Committee (NICR 16/17 Paper 39). To ensure that the content and design of questions was suitable for the target sample, the survey was developed in consultation with a panel of health professionals who work with primary care practitioners. Prior to the main fieldwork the survey was also piloted tested with 50 health professionals by the market research company (ResearchNow; Now Dynata). All participants provided written consent before completing the survey.

\section{Consent for publication}

Not applicable.

\section{Competing interests}

No conflicts of interest to declare.

\section{Author details}

${ }^{1}$ Cancer Policy Research Centre, Cancer Research UK, 2 Redman Place, London E20 1JQ, UK. ${ }^{2}$ Institute for Social Marketing and Health, Faculty of Health Sciences and Sport, University of Stirling, Stirling FK9 4LA, UK. ${ }^{3}$ Cancer Intelligence, Cancer Research UK, 2 Redman Place, London E20 1JQ, UK.

Received: 13 December 2019 Accepted: 9 June 2020

Published online: 19 June 2020

\section{References}

1. Baker C. Obesity statistics, briefing paper (number 3336). 2019 https:// researchbriefings.files.parliament.uk/documents/SN03336/SN03336.pdf. Last accessed 6 June 2020 .

2. National Health Service Digital. Statistics on obesity, physical activity and diet, England. 2019. https://digital.nhs.uk/data-and-information/publications/ statistical/statistics-on-obesity-physical-activity-and-diet/statistics-on-obesityphysical-activity-and-diet-england-2019. Last accessed 6 June 2020.

3. HM Government. Guidance - Health matters: Obesity and the food environment. https://www.gov.uk/government/publications/health-mattersobesity-and-the-food-environment/health-matters-obesity-and-the-foodenvironment\%2D\%2D2. 2017. Last accessed 6 June 2020

4. Bhaskaran K, Douglas I, Forbes H, dos-Santos-Silva I, Leon DA, Smeeth L. Body-mass index and risk of 22 specific cancers: a population-based cohort study of 5.24 million UK adults. Lancet. 2014:384(9945):755-65.

5. Brown KF, Rumgay H, Dunlop C, Ryan M, Quartly F, Cox A, Deas A, EllissBrookes L, Gavin A, Hounsome L, Huws D, Ormiston-Smith N, Shelton J, White C, Parkin DM. The fraction of cancer attributable to modifiable risk factors in England, Wales, Scotland, Northern Ireland, and the United Kingdom in 2015. Br J Cancer. 2018;118:1130-41.

6. National Health Service Digital. Patients registered at a GP practice, September 2019. 2019. https://digital.nhs.uk/data-and-information/ publications/statistical/patients-registered-at-a-gp-practice/september-2019. Last accessed 6 June 2020

7. Halbert $\mathrm{CH}$, Jefferson M, Melvin $\mathrm{CL}$, Rice L, Chukwuka KM. Provider advice about weight loss in a primary care sample of obese and overweight patients. J Prim Care Community Health. 2017;8(4):239-46.
8. Post RE, Mainous AG, Gregorie SH, Knoll ME, Diaz VA, Saxena SK. The influence of physician acknowledgement of patients, weight status on patient perceptions of overweight and obesity in the United States. Arch Intern Med. 2011;171(4):316-21.

9. Aveyard P, Lewis A, Tearne S, Hood K, Christian-Brown A, Adab P, et al. Screening and brief interventions for obesity in primary care: a parallel, twoarm, randomised trial. Lancet. 2016;388:2492-500.

10. Retat M, Pimpin L, Webber $L$, Jaccard A, Lewis A, Tearne $S$, et al. Screening and brief intervention for obesity in primary care: cost-effectiveness analysis in the BWeL trial. Int J Obes. 2019;43(1):2066-75.

11. Jackson SE, Wardle J, Johnson F, Finer N, Beeken RJ. The impact of a health professional recommendation on weight loss attempts in overweight and obese British adults: a cross-sectional analysis. BMJ Open. 2013;3:e003693.

12. Rose SA, Poynter PS, Anderson JW, Noar SM, Conigliaro J. Physician weight loss advice and patient weight loss behaviour change: a literature review and meta-analysis of survey data. Int J Obes. 2013;37(1):118-28.

13. Logue J, Allardice G, Gillies M, Forde L, Morrison DS. Outcomes of a specialist weight management programme in the UK National Health Services: prospective study of 1838 patients. BMJ Open. 2014;4(1):e003747.

14. Blane DN, Macdonald S, O'Donnell CA. What works and why in the identification and referral of adults with comorbid in primary care: a realistic review. Obes Rev. 2020;41(4):e12979.

15. Blane DN, Macdonald S, Morrison D, O'Donnell CA. The role of primary care in adult weight management: qualitative interviews with key stakeholders in weight management services. BMC Health Serv Res. 2017;17(1):764.

16. Public Health England. Let's talk about weight: A step-by-step guide to brief interventions with adults for health and care professional. $2017 \mathrm{https}: / /$ assets.publishing.service.gov.uk/government/uploads/system/uploads/ attachment_data/file/620405/weight_management_toolkit_Let_s_talk_ about weight.pdf. Last accessed 6 June 2020

17. Brown J, West R, Angus C, Beard E, Brennan A, Drummond C, et al. Comparison of brief interventions in primary care on smoking and excessive alcohol consumption: a population survey in England. Br J Gen Pract. 2016; 66(642):1-9.

18. National Institute for Health and Care Excellence. Alcohol-use disorders: Diagnosis, assessment and management of harmful drinking (high-risk drinking) and alcohol dependence [clinical guideline: CG115]. 2011. https:// www.nice.org.uk/guidance/cg115/chapter/1-Guidance. Last accessed 6 June 2020.

19. National Institute for Health and Care Excellence. Stop smoking interventions and services [NICE guideline NG92]. 2019. https://www.nice. org.uk/guidance/ng92/chapter/Recommendations\#engaging-with-peoplewho-smoke. Last accessed 6 June 2020.

20. Torti J, Luig T, Borowitz M, Johnson JA, Sharma AM, Campbell-Scherer DL. The 5 As team patient study. Patient perspectives on the role of primary care in obesity management. BMC Fam Pract. 2017;18:19.

21. Tham M, Young D. The role of the general practitioner in weight management in primary care: a cross-sectional study in general practice. BMC Fam Pract. 2008;15(9):66.

22. McHale CT, Laidlaw AH, Cecil JE. Primary care patient and practitioner views of weight and weight-related discussion: a mixed-method study. BMJ Open. 2019;10:e034023.

23. Laidlaw A, Napier C, Neville F, Collinson A, Cecil JE. Talking about weight talk: primary care practitioner knowledge, attitudes, and practice. J Commun Healthc. 2019;12(3/4):145-53.

24. Hooper L, Anderson AS, Birch J, Forster AS, Rosenberg G, Bauld L, Vohra J. Public awareness and healthcare professional advice for obesity as a risk factor for cancer in the UK: a cross-sectional survey. J Public Health. 2017; 40(4):797-805.

25. Booth HP, Prevost AT, Guilliford MC. Access to weight reduction interventions for overweight and obese patients in UK primary care: population-based cohort study. BMJ Open. 2015;5:e006642.

26. McLaughlin JC, Hamilton K, Kipping R. Epidemiology of adult overweight recording and management by UK GPs: a systematic review. $\mathrm{Br} J$ Gen Pract. 2017;67(663):676-83

27. Abid A, Galuska D, Khan LK, Gillespie C, Ford ES, Serdula MK. Are healthcare professionals advising obese patient's obese patients to lose weight? A trend analysis. Med Gen Med. 2005;7(4):10.

28. Kirk SF, Tytus R, Tsuyuki RT, Sharma AM. Weight management experiences of overweight and obese Canadian adults: Findings from a national survey. Chronic Dis Inj Can. 2012;32(2):63-9. 
29. Nicholson BD, Ayeyard P, Bankhead CR, Hamilton W, Hobbs FDR, Lay-Flurrie S. Determinants and extent of weight recording in UK primary care: an analysis of 5 million adults' electronic health records from 2000 to 2017. BMC Med. 2019;17:222

30. Michie S. Talking to primary care patients about weight: a study of GPS and practice nurses in the UK. Psychol Health Med. 2007:12(5):521-5.

31. Ananthakumar $T$, Jones NR, Hinton L, Aveyard P. Clinical encounters about obesity: systematic review of patients' perspectives. Clin Obes. 2020;10(1): 12347.

32. Laidlaw A, McHale C, Locke H, Cecil J. Talk weight: an observational study of communication about patient weight in primary care consultation. Prim Health Care Res Dev. 2015;16(3):309-15.

33. Blane DN, McLoone P, Morrison D, Macdonald S, O'Donnell CA. Patient and practice characteristics predicting attendance and completion at a specialist weight management service in the UK: a cross-sectional study. BMJ Open. 2017;7:e018286.

34. Rosenberg G, Crawford C, Bullock S, Petty R, Vohra J. Smoking cessation in primary care: a cross-sectional survey of primary care health practitioners in the UK and the use of very brief advice. 2019. https://www.cancerresearchuk.org/ sites/default/files/tobacco_pc_report_to_publish_-_full12.pdf. Last accessed 6 June 2020.

35. National Health Service Clinical Commissioners. About CCGs. https://www. nhscc.org/ccgs/. Last accessed 6 June 2020.

36. National Health Services Wales. Structure. http://www.wales.nhs.uk/ nhswalesaboutus/structure. Last accessed 6 June 2020

37. National Health Service Scotland. About NHS Scotland. https://www.scot. nhs.uk/about-nhs-scotland/. Last accessed 6 June 2020

38. Bos-Touwen ID, Trappenburg JCA, van der Wulp I, Schuurmans MK, de Wit NJ. Patient factors that influence clinical decision making in selfmanagement support: a clinical vignette study. PLoS One. 2017;12(2): e0171251.

39. Veloski J, Tai S, Evans AS, Nash DB. Clinical vignette-based surveys: a took for assessing physician practice variation. Am J Med Qual. 2005;20(3):151-7.

40. Peabody JW, Luck J, Glassman P, Jain S, Hansen J, Spell M, Lee M. Measuring the quality of physician practice by using clinical vignettes: a prospective validation study. Ann Intern Med. 2004;141(10):771-80.

41. National Institute for Health and Care Excellence. Obesity: identification, assessment and management [Clinical guidelines, CG189]. 2014. https:// www.nice.org.uk/guidance/cg189. Last accessed 6 June 2020.

42. National Institute for Health and Care Excellence. Indicators for the NICE menu for the Quality and Outcomes Framework [Area Indicator: Obesity and overweight; Indicator: NM128]. 2015. https://www.nice.org.uk/Media/ Default/Standards-and-indicators/QOF\%20Indicator\%20Key\%20documents/ nm128-obesity-register-nice-guidance.pdf. Last accessed 6 June 2020.

43. Royal Colleague of Physicians. Action on obesity: Comprehensive care for all, reporting of a working party. 2015. https://www.rcplondon.ac.uk/ projects/outputs/action-obesity-comprehensive-care-all. Last accessed 6 June 2020.

44. Dewhurst A, Peters S, Devereux-Fitzgerald A, Hart J. Physicians' views and experiences of discussing weight management with routine clinical consultations: a thematic synthesis. Patient Educ Couns. 2017;100(5):897908 .

45. Blackburn M, Stathi A, Keogh E, Ecclestone, et al. Raising the topic of weight in general practice: Perspectives of GPS and primary care nurses. BMJ Open. 2015:5(8):e008546.

46. Leverence RR, Williams RL, Sussman A, Crabtree RF, Net Clinicians RIOS. Obesity counselling and guidelines in primary care: a qualitative study. Am J Prev Med. 2007;32(4):334-9.

47. Nolan C, Dehan A, Wylie A, Jones R. Practice nurses and obesity: professional and practice-based factors affecting role adequacy and role legitimacy. Prim Health Care Res Dev. 2012;13(4):353-63.

48. Blackburn $M$, Stathi A. Moral discourse in general practitioners' accounts of obesity communication. Soc Sci Med. 2019;230:166-73.

49. Mazza D, McCarthy E, Carey M, Turner L, Harris M. " $90 \%$ of the time, it's not just weight": general practitioner and practice staff perspectives regarding the barriers and enables to obesity guideline implementation. Obes Res Clin Pract. 2019;13(4):398-403.

50. Schmied VA, Duff M, Dahlen HG, Mills AE, Kolt GS. 'Not waving but drowning': a study of the experiences and concerns of midwives and other health professionals caring for obese childbearing women. Midwifery. 2011; 27(4):424-30.
51. Mercer SW, Tessier S. A qualitative study of general practitioners' and practice nurses attitude and obesity management in primary care. Health Bull (Edinb). 2001;59(4):248-53.

52. van Dillen SME, Hiddink GJ. To what extent do primary care practice nurses act as case managers lifestyle counselling regarding weight management? A systematic review. BMC Fam Pract. 2014;15:197.

53. Epstein L. A qualitative study of GPs' views of treating obesity. Br J Gen Pract. 2005;55(519):750-4.

54. Kahan SI. Practical strategies for engaging individuals with obesity in primary care. Mayo Clin Proc. 2018;93(3):351-9.

55. Tang JW, Kushner RF, Cameron KA, Hicks B, Cooper AJ, Baker DW. Electronic tools to assist with identification and counselling for overweight patients: a randomised controlled trial. J Gen Inter Med. 2012;27(8):933-9.

56. O'Donnell A, Angus C, Hanratty B, Hamilton FL, Petersen I, Kaner E. Impact of the introduction and withdrawal of financial incentives on the delivery of alcohol screening and brief advice in English primary health care: an interrupted time-series analysis. Addiction. 2020;115(1):49-60.

57. Hamilton F, Greaves F, Majeed A, Millett C. Effectiveness of providing financial incentives to healthcare professionals for smoking cessation activities: systematic review. Tob Control. 2013;22(1):3-8.

\section{Publisher's Note}

Springer Nature remains neutral with regard to jurisdictional claims in published maps and institutional affiliations.
Ready to submit your research? Choose BMC and benefit from:

- fast, convenient online submission

- thorough peer review by experienced researchers in your field

- rapid publication on acceptance

- support for research data, including large and complex data types

- gold Open Access which fosters wider collaboration and increased citations

- maximum visibility for your research: over $100 \mathrm{M}$ website views per year

At $\mathrm{BMC}$, research is always in progress.

Learn more biomedcentral.com/submissions 